\title{
Ultrasonic velocity and attenuation of glass ballotini in viscous and viscoelastic fluids
}

\author{
G.H. Meeten* and N.E. Sherman** $\dagger$ \\ *Schlumberger Cambridge Research, PO Box 153, Cambridge CB3 OHG, UK \\ **Department of Chemical Engineering, University of Cambridge, Pembroke Street, \\ Cambridge CB2 3RA, UK \\ Received 5 May 1992; revised 10 October 1992
}

\begin{abstract}
Measurements are reported of the attenuation, $\alpha$, and the velocity, $c$, of $1-5 \mathrm{MHz}$ compressional wave ultrasound in suspensions of glass ballotini in Newtonian and non-Newtonian base fluids. For the Newtonian fluids, good agreement is found between the measured $\alpha$ and $c$, and the $\alpha$ and $c$ obtained from the Urick and the Ament expressions, using the same value for the base fluid's viscosity. For the non-Newtonian base fluids, this agreement was absent. The existence of shear elasticity $G$ in these fluids is suggested to explain the results. By incorporating elasticity into the Urick and the Ament theories the disagreement is resolved, and values of $G$ are found which are in order-of-magnitude agreement with those found at the same frequency by another method. A test is proposed of a recent assertion that simple molecular fluids possess a shear elasticity.
\end{abstract}

Keywords: fluids; glass ballotini; velocity; attenuation

The use of ultrasound to characterize suspensions is a large and growing application, as recently reviewed by McClements ${ }^{1}$. Despite this, there have been relatively few basic and quantitative investigations, where the ultrasonic propagation parameters such as velocity $(c)$ and attenuation $(\alpha)$ have been measured for wellcharacterized suspensions, and the results compared with theoretical expressions. One of our aims was to use ultrasonics to probe the rheology of fluids. This required a granular rather than colloidal particle size, i.e. particles of about $10-100 \mu \mathrm{m}$ in diameter. Here, the thermal scattering contribution to the attenuation was negligible, leaving the visco-inertial scattering term dominant such that $\alpha$ and $c$ were sensitive to the local rheology of the fluid surrounding the particles. To ensure dominance of the visco-inertial contribution, a significant density difference between the particles and the surrounding fluid was necessary. This constraint, and that of the large diameters required relative to the commonly available polymer latices, disallowed the use of accurately monodisperse particles. Hence, glass ballotini, sieved into narrow particle size fractions and sized by light scattering and optical microscopy, were used.

Work similar to ours, and using the same ballotini, was reported by Rahalkar et al. ${ }^{2}$, who studied the effects of adding ballotini to aqueous solutions of a xanthan polymer. Their results agreed only qualitatively with existing theories for suspensions. They attributed this to the viscoelasticity of the polymer gel network.

Drilling muds are a suspension of mineral grains in a non-Newtonian base fluid, typically a polymer or clay

†Present address: DRA, Farnborough, Hampshire GU14 6TD, UK gel. The network's yield stress is designed to prevent sedimentation of granular particles such as barite (added to increase the mud density) or rock particles (which originate from the drill bit). The ultrasonic properties of drilling mud have applications in the interpretation of signals from downhole ultrasonic tools ${ }^{3}$ and in the monitoring of mud flows ${ }^{4}$. The ultrasonic velocity and attenuation have been shown ${ }^{5}$ to be sensitive to the spontaneous gelation of drilling mud clays. Here we investigate the effects of adding granular particles to these fluids, simulating the particles of barite and rock in real drilling muds.

\section{Theoretical details}

\section{Viscous base fluid}

We assume non-interacting spherical particles, of diameter $2 a$, small compared with the ultrasonic wavelength $\lambda$, i.e. $2 a<\lambda / 10$. The Urick expression ${ }^{6}$ for the excess amplitude attenuation per unit volume fraction of particles $\phi$ is

$\frac{\alpha}{\phi}=\frac{k^{4} a^{3}}{6}+\frac{k s(r-1)^{2}}{2 s^{2}+2(r+T)^{2}}$

where $k=2 \pi / \lambda$ and $r=\rho^{\prime} / \rho$ is the ratio of particle to base fluid densities. The base fluid rheology is effective through the hydrodynamic skin depth $\delta$. For a Newtonian fluid of viscosity $\eta$,

$\delta=\left(\frac{2 \eta}{\omega \rho}\right)^{1 / 2}$

at a pulsatance $\omega$. The terms $T$ and $s$ in Equation (1) are 
then defined by

$T=\frac{1}{2}+\frac{9 \delta}{4 a}$

and

$s=\frac{9 \delta}{4 a}\left(1+\frac{\delta}{a}\right)=\frac{1}{18}(2 T-1)(4 T+7)$

For the material properties and particle diameters considered here $\delta / a<1,0.2$ being typical. Expanding Equation (1) in powers of $\delta / a$ to the second order gives

$\frac{\alpha}{\phi}=\frac{k^{4} a^{3}}{6}+\left(\frac{r-1}{2 r+1}\right)^{2} \frac{9 k \delta}{2 a}\left(1+\frac{\delta}{a}\left(1-\frac{18 r}{(2 r+1)^{2}}\right)\right)$

Thus, terms in $(\delta / a)^{2}$ vanish when $1=18 r /(2 r+1)^{2}$, giving $r=(7 \pm \sqrt{45}) / 4$, i.e. for $r=0.0729$ or 3.427 . For the ballotini $\left(\rho^{\prime} \sim 2900 \mathrm{~kg} \mathrm{~m}^{-3}\right)$ in our base fluids $\left(\rho \sim 1000 \mathrm{~kg} \mathrm{~m}^{-3}\right) r$ is sufficiently close to 3.427 so that the term in $(\delta / a)^{2}$ contributes only a few percent to $\alpha / \phi$; less than the experimental uncertainty. Thus, Equation (1) simplifies to

$\frac{\alpha}{\phi}=\frac{k^{4} a^{3}}{6}+\frac{9 k \delta}{2 a}\left(\frac{r-1}{2 r+1}\right)^{2}$

Although obtained originally by Urick using a nonscattering argument, Equation (6) is identical, up to $(\delta / a)^{1}$, to the expression of Hay and Mercer ${ }^{7}$, derived on the basis of scattering theory for a solid, elastic sphere.

For the phase velocity $c$ we use the expression of Ament ${ }^{8,9}$. The phase slowness is

$\frac{1}{c}=\sqrt{\bar{K} \rho^{*}}$

The volume average compressibility $\bar{K}$ is

$\bar{K}=K^{\prime} \phi+K(1-\phi)$

where $K^{\prime}$ and $K$ refer to the compressibility of the ballotini and the base fluid, respectively. The effective density is

$\rho^{*}=\bar{\rho}+z$

where the volume average density is

$\bar{\rho}=\rho^{\prime} \phi+\rho(1-\phi)$

The base fluid rheology enters $c$ through

$z=-\frac{2\left(\rho^{\prime}-\rho\right)^{2} \phi(1-\phi) A}{A^{2}+C^{2}}$

where

$A=2\left(\rho^{\prime}-\rho\right)(1-\phi)+2 \rho(1+T)$

and

$C=2 \rho s$

$T$ and $s$ being defined in Equations (3) and (4). Using Equations (8)-(13) and taking only terms linear in $\phi$, Equation (7) gives

$\frac{1}{\phi}\left(\frac{c_{0}}{c}-1\right)=\frac{K^{\prime}-K}{2 K}+\frac{3}{2} \frac{r-1}{2 r+1}+\frac{9 \delta}{2 a}\left(\frac{r-1}{2 r+1}\right)^{2}$

where $c_{0}$ is the velocity in the base fluid

\section{Viscoelastic base fluid}

For a viscoelastic base fluid, the viscosity $\eta$ in the previous expressions for $\alpha$ and $c$ become complex. Thus, $\eta$ is replaced by $\eta+i G / \omega$, where $\mathrm{i}^{2}=-1$ and $G$ is the shear modulus of the base fluid. Hence, the skin depth $\delta$ in Equation (6) and Equation (7) also becomes complex, and is written $\delta^{\prime}+\mathrm{i} \delta^{\prime \prime}$, where $\delta^{\prime}$ and $\delta^{\prime \prime}$ are real. The complex wavevector may be written

$\boldsymbol{k}=\frac{\omega}{c}+\mathrm{i} \alpha$

We replace $\delta$ in Equation (6) and Equation (14) by $\delta^{\prime}+\mathrm{i} \delta^{\prime \prime}$ and use these complex versions of $1 / c$ and $\alpha$ in Equation (15). Now $\omega / c=\operatorname{Re} k$ and $\alpha=-\mathrm{i} \operatorname{Im} k$, thus

$\frac{\alpha}{\phi}=\frac{a^{3} k^{4}}{6}+\frac{9 k}{2 a}\left(\frac{r-1}{2 r+1}\right)^{2}\left(\delta^{\prime}+\delta^{\prime \prime}\right)$

and

$$
\begin{aligned}
\frac{1}{\phi}\left(\frac{c_{0}}{c}-1\right)= & \frac{K^{\prime}-K}{2 K}+\frac{3}{2} \frac{r-1}{2 r+1} \\
& +\frac{9}{2 a}\left(\frac{r-1}{2 r+1}\right)^{2}\left(\delta^{\prime}-\delta^{\prime \prime}\right)
\end{aligned}
$$

Comparing Equation (16) and Equation (17) with Equation (6) and Equation (14) shows that if the base fluid acquires elasticity, the effect is to increase both $\alpha$ and $c$. It will be convenient to write

$\delta^{\prime}=\frac{\delta}{\sqrt{2}}\left(\left[1+Q^{2}\right]^{1 / 2}+1\right)^{1 / 2}$

and

$\delta^{\prime \prime}=\frac{\delta}{\sqrt{2}}\left(\left[1+Q^{2}\right]^{1 / 2}-1\right)^{1 / 2}$

where $Q=G / \omega \eta$ and $\delta$ is defined in Equation (2).

\section{Polydispersity}

It was found that the particle radii $(a)$ of the seived ballotini fitted closely a Gaussian log-normal probability function

$f(x)=f(\bar{x}) \exp -\left(\frac{\bar{x}-x}{2 \sigma}\right)^{2}$

where $x=\ln a, \bar{x}$ is the mean logarithmic radius, and $\sigma$ is the standard deviation of $x$ about $\bar{x}$. The volumeaverage of functions such as $a^{n}$, where $n$ is an integer, is then given by

$\overline{\mathrm{a}^{n}}=\int_{-\infty}^{\infty} a^{n} f(x) \mathrm{d} x / \int_{-\infty}^{\infty} f(x) \mathrm{d} x=(\bar{x})^{n} \exp (n \sigma)^{2}$

This result is readily applied to theoretical expressions where powers of the particle radius exist in linear combinations. Thus, using Equation (21) shows that the polydisperse version of Equation (6) becomes

$\frac{\alpha}{\phi}=\frac{k^{4} a_{0}^{3}}{6} \exp (3 \sigma)^{2}+\left(\frac{r-1}{2 r+1}\right)^{2} \frac{9 k \delta}{2 a_{0}} \exp \sigma^{2}$

where $a_{0}$ is defined by $\ln a_{0}=\overline{\ln a}$. Similarly, Equation (14) becomes

$\frac{1}{\phi}\left(\frac{c_{0}}{c}-1\right)=\frac{K^{\prime}-K}{2 K}+\frac{3}{2} \frac{r-1}{2 r+1}+\frac{9 \delta}{2 a}\left(\frac{r-1}{2 r+1}\right)^{2} \exp \sigma^{2}$ 
It is, however, not possible to write down a polydisperse version of Equation (7) with the same ease, owing to the complicated way that $a$ enters this equation, through $z$. Facing the same problem, McClements ${ }^{10}$ used the Sauter mean radius. On the basis of the above, we see no justification for this approach. We appreciate however, that McClements' main interest was the variation of ultrasonic parameters with frequency, rather than particle radius, so that a satisfactory empirical correction for polydispersity may have been possible. We compared our velocity data with Equation (7), using the mean radius $a_{0}$ rather than attempting a complicated correction for polydispersity. Fair agreement between the ultrasonic and the rheologically-measured viscosities is obtained.

\section{Apparatus}

\section{Ultrasonic measurements}

Accurate measurements of $\alpha$ and $c$ were required. Various methods of measuring these have been compared ${ }^{5}$, where it was concluded that the best methods for $c$ and $\alpha$ were the pulse-echo overlap (PEO), and tone burst, respectively. These were essentially single frequency methods, and changes in the operating frequency were feasible within the range 1-5 $\mathrm{MHz}$. A full description of the apparatus and method is given by Champion et al. ${ }^{5}$ The same equipment was used for the measurements described here.

\section{Fluids and particles}

The Newtonian fluids were glycerol, and a polypropylene glycol (PPG) of molecular weight 2025. Densities were measured to within $\sim 1 \%$ using a weighing bottle. Viscositics were measured using a Haake rheometer over a temperature range of $17-23^{\circ} \mathrm{C}$. The viscosities were sufficiently large $(\sim \mathrm{Pa} s)$ to be able to disregard ballotini sedimentation over the measurement time.

The non-Newtonian fluids were both suspensions of bentonite clays. The water-based suspension was made by adding Bentopharm B20 (a pharmaceutical grade sodium montmorillonite: Bromhead and Denison, UK), to deionized water. A volume fraction range $0.01-0.03$ gave a gelatinous suspension of yield stress sufficient to prevent sedimentation of the more dense ballotini. A rhcological description of Bentopharm B20 suspensions has been given by Heath and Tadros ${ }^{11}$. It was important that no air bubbles were trapped in these suspensions by the yield stress, and suspensions were de-aired for about 1 hour in a bell jar held at a pressure close to -1 bar.

The oil-based bentonite suspension was prepared by mixing Carbogel clay with Milclean oil and the appropriate surfactants. (Carbogel and Milclean are products of Milchem, USA.) This produced another gelatinous fluid which was, through its yield stress, capable of suspending ballotini particles without sedimentation.

\section{Partic/es}

The particles were lead glass ballotini (Jencons No. 18), of nominal diameter $40-75 \mu \mathrm{m}$. Inspection by optical microscope showed excellent sphericity, and also the presence of particles in the diameter ranges $30-100 \mu \mathrm{m}$. The glass density was measured on a de-aired sample, using a liquid displacement method, giving $\rho^{\prime}=2900 \pm 20$ $\mathrm{kg} \mathrm{m}{ }^{-3}$. This compares with $2950 \mathrm{~kg} \mathrm{~m}^{-3}$ given by Jencons.

Over the $30-100 \mu \mathrm{m}$ diameter size range, taking for example $5 \mathrm{MHz}$ with glycerol as the base fluid, the dominant attenuation mechanism changes from scattering to viscous loss. For a $30 \mu \mathrm{m}$ diameter sphere $\alpha_{\text {sca }} / \alpha_{\text {vis }} \sim$ 0.03 , whereas for a $100 \mu \mathrm{m}$ sphere, $\alpha_{\text {sca }} / \alpha_{\text {vis }} \sim 4$. This shift from one to another mechanism was ideal for the purpose of checking the ultrasonic theories of $\alpha$ and $c$. Sieving and particle size measurement was undertaken to produce batches of well-characterized ballotini in sufficient amount for the ultrasonic measurements. A nest of Endecotts sieves was used, with sieve mesh apertures of $38,45,53,63,75,90$ and $125 \mu \mathrm{m}$. The ballotini were dried at $35^{\circ} \mathrm{C}$ for $30 \mathrm{~min}$ to reduce dampness and sticking, and poured into the coarsest sieve at the top of the nest, which was tapped and shaken. Before removal from a sieve the ballotini were gently brushed across it to ensure that small particles passed through to the next sieve. Batches of $23 \mathrm{~g}$ were seived in this way to produce size fractions of smaller polydispersity than the as-received sample.

Size distribution measurements were made using a Leeds and Northrup Microtrac particle size analyser. This uses light scattering from a very dilute $\left(\phi \sim 10^{-4}\right)$ dispersion in water. The Microtrac gave mean diameter, standard deviation, and a diameter distribution consisting of the relative volume of ballotini in fixed diameter ranges. The reliability of the Microtrac data was tested by comparing with data from a Seescan image analysis system. Photomicrographs of the ballotini were digitized in terms of optical density, and the data interpreted in terms of diameter distribution by the image analyser. The data points of Figure 1 compare the Microtrac with the Seescan results for the as-received ballotini. The curves of Figure 1 are fits of the $\log$-normal distribution to the two data sets. The close agreement between the methods suggested reliability of both, and the Microtrac method was used routinely to obtain $a_{0}$ and $\sigma$. Table $I$ shows these parameters for the as-received and the sieved ballotini, where ( ) indicates image analyser data.

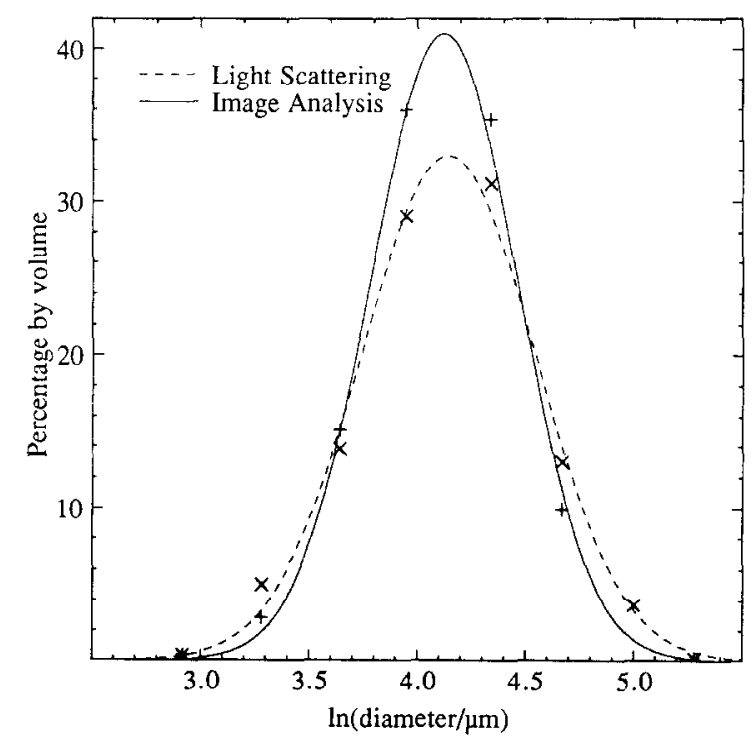

Figure 1 Percentage by volume versus $\ln$ (diameter $[\mu \mathrm{m}]$ ) for Jencons number 18 ballotini. Upright crosses; image analysis. Diagonal crosses; light scattering 
Table $1 a_{0}$ and $\sigma$ for the as-received and sieved ballotini

\begin{tabular}{|lll|}
\hline Sieve range $(\mu \mathrm{m})$ & $a_{0}(\mu \mathrm{m})$ & $\sigma$ \\
\hline$<19$ & 15.8 & 0.3 \\
$19-22.5$ & 19.9 & 0.25 \\
$22.5-26.5$ & 25.0 & 0.24 \\
$26.5-31.5$ & 28.1 & 0.24 \\
$31.5-37.5$ & 31.3 & 0.27 \\
$37.5-45.0$ & 40.4 & 0.29 \\
$45.0-62.5$ & 44.3 & 0.33 \\
as-received & $31.5(30.5)$ & $0.41(0.35)$ \\
\hline
\end{tabular}

\section{Results}

\section{Newtonian fluids}

Attenuation. Preliminary measurements were made to establish the range of validity of the theory, i.e. where $\alpha \propto \phi$. Figure 2 shows that $0<\phi<0.03$ allows both linearity, and also an $\alpha$ large enough to obtain good data. Measurements of $\alpha / \phi$ were then made for the various sieved fractions of Table 1. Figure 3 shows data at $5 \mathrm{MHz}$, together with a line described by Equation (22). As the least well-defined quantity of Equation (22) was $\sigma$, the data points and the theoretical line in Figure 3 were fitted by assuming $\sigma$ to be constant throughout the sieved fractions, and allowing it to vary to obtain the best fit. The resulting $\sigma=0.21 \pm 0.04$ was in good agreement with the Microtrac particle size analysis of Table 1 . In the above comparison the largest value of $\lambda / a_{0}$ was about 0.1 , for which the dipole scattering (Rayleigh region) approximation incorporated into Equation (6) and Equation (22) should be good. Trespass into the above-Rayleigh region is shown by the divergence of data from theory (Equation 22) in Figure 4. Here, a poor fit between data and the prediction of Equation (22) is seen to occur at $a_{0}>30$, corresponding to $a_{0} / \lambda \sim 0.1$. Below this, the fit between data and Equation (22) is seen to be good. The limit found above agrees well with the estimate of $a_{0} / \lambda=0.1$ of Allegra and Hawley ${ }^{12}$, found by calculating the scattering terms of $\alpha$ for Rayleigh spheres and above. Data and theory (Equation 22) are further compared in Figure 5. At a frequency of $2.25 \mathrm{MHz}$ and using PPG 2025 as the base fluid, $a_{0} / \lambda<0.07$ for all ballotini, and the fit is seen to be good.

Velocity. Figure 6 shows the measured velocity $(c)$ data at $1 \mathrm{MHz}$ versus volume fraction $\phi$ for the smallest sieved ballotini fraction, $a_{0}=15.8 \mu \mathrm{m}$. The broken curve shows the prediction of Equation (7) if $\eta=1.33 \pm 0.1 \mathrm{~Pa} \mathrm{~s}$ is used for the fit, i.e. that of glycerol at the temperature $\left(20^{\circ} \mathrm{C}\right)$ of measurement. If $\eta$ in Equation (7) is assumed to be the macroscopic viscosity of the suspension it can be described by

$\eta=\eta_{0}\left(1+K_{2} \phi+K_{3} \phi^{2}\right)$

where the classical Einstein result is $K_{2}=5 / 2$, and the magnitude of $K_{3}$ depends on the nature and the state of the suspension. We may neglect Brownian motion for even the smallest diameter ballotini, and ultrasonic fields imply a high frequency, low shear, oscillatory flow. For these conditions $K_{3}=5.2$ has been derived ${ }^{13,14}$. Using Equation (24) with $K_{3}=5.2$ for $\eta$ in Equation (7) gave the solid line in Figure 6 where $\eta_{0}=2.1 \pm 0.1 \mathrm{~Pa}$ s. Thus, the fit to data is much improved compared with taking a $\phi$-independent base fluid viscosity, and a fair agreement is found between $\eta_{0}$ and the viscosity $\eta$ of the base fluid.

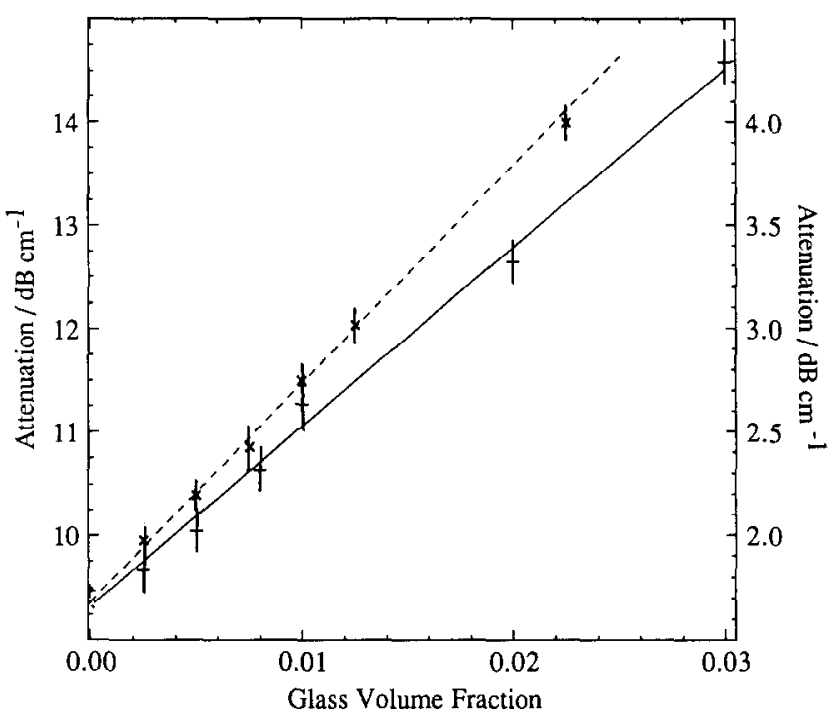

Figure 2 Attenuation versus ballotini volume fraction for unsieved ballotini at $20^{\circ} \mathrm{C}$. Solid curve (left ordinate); glycerol at $5 \mathrm{MHz}$. Broken curve (right ordinate); PPG 2025 at $2.25 \mathrm{MHz}$

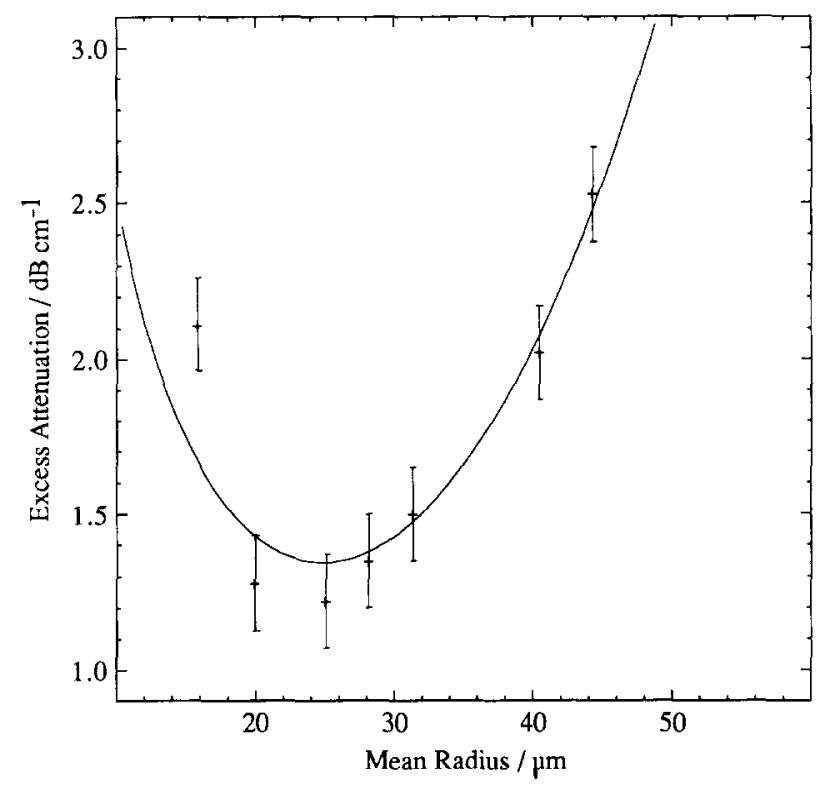

Figure 3 Excess attenuation versus mean radius $a_{0}$ for ballotini of $\phi=0.0124$ in $95 \%$ by volume glycerol aqueous solution at $20^{\circ} \mathrm{C}$ and $5 \mathrm{MHz}$

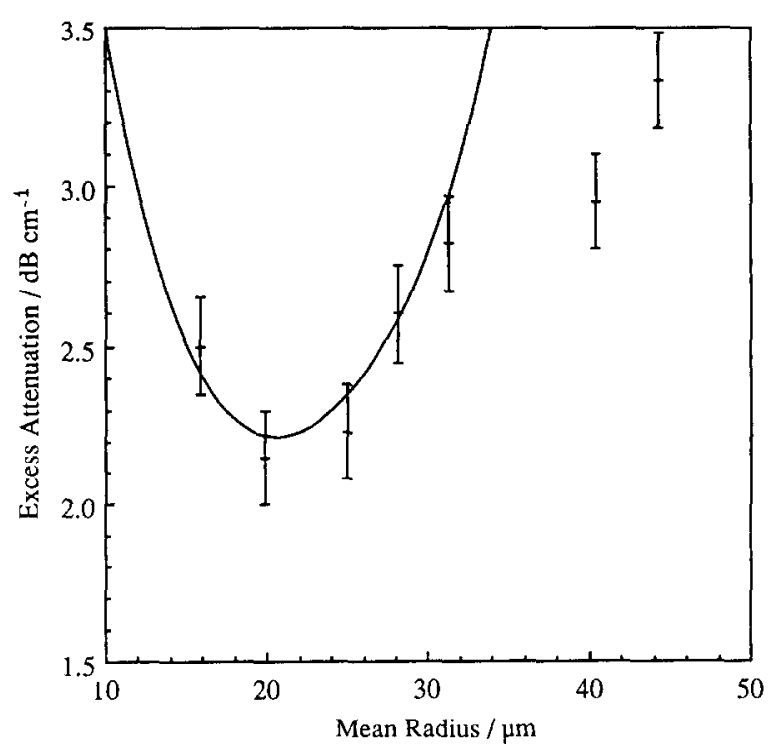

Figure 4 Excess attenuation versus mean radius $a_{0}$ for ballotini of $\phi=0.01$ in PPG2025 at $20^{\circ} \mathrm{C}$ and $5 \mathrm{MHz}$ 


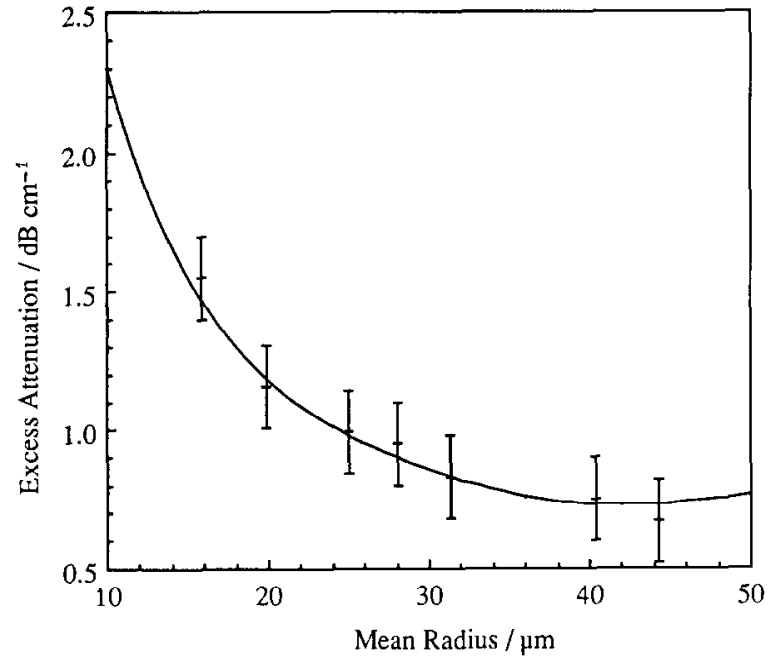

Figure 5 Excess attenuation versus mean radius $a_{0}$ for ballotini of $\phi=0.01$ in PPG 2025 at $20^{\circ} \mathrm{C}$ and $2.25 \mathrm{MHz}$

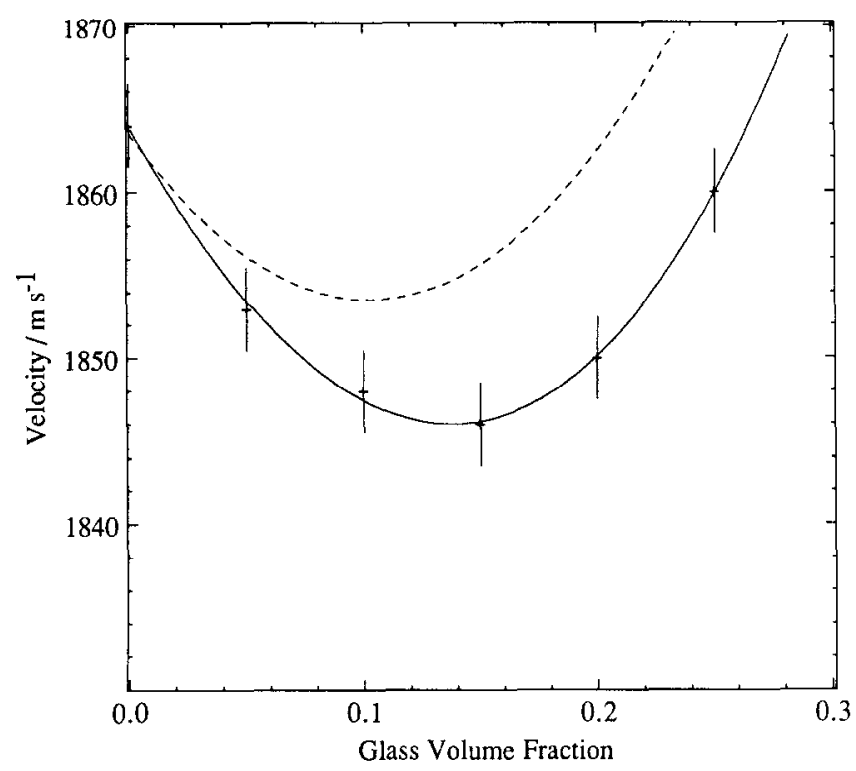

Figure 6 Velocity versus ballotini volume fraction for $a_{0}=15.8 \mu \mathrm{m}$ ballotini in glycerol at $20^{\circ} \mathrm{C}$ and $1 \mathrm{MHz}$

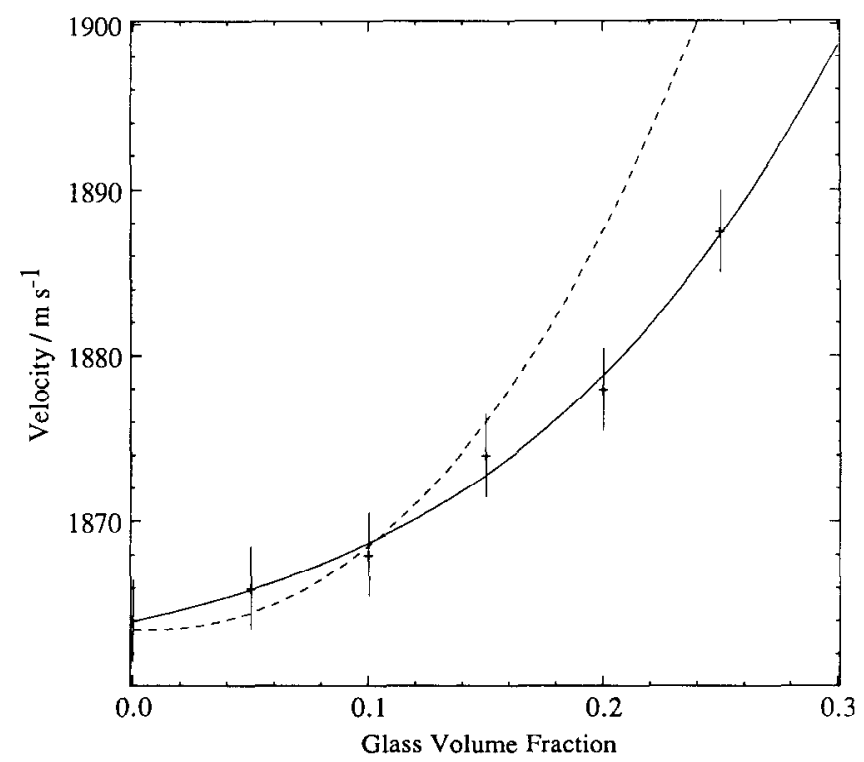

Figure 7 Velocity versus ballotini volume fraction for $a_{0}=15.8 \mu \mathrm{m}$ ballotini in glycerol at $20^{\circ} \mathrm{C}$ and $5 \mathrm{MHz}$
Measurements were made of $c$ for the same ballotini fraction at $5 \mathrm{MHz}$, the data being shown in Figure 7. The solid curve shows an excellent fit to the data if $\eta$ was allowed to vary with $\phi$ according to Equation (24) with $K_{3}=5.2$; a base fluid viscosity of $1.30 \mathrm{~Pa} \mathrm{~s}$ was obtained for $\eta_{0}$, compared with $1.33 \mathrm{~Pa} \mathrm{~s}$ measured rheometrically. The broken line shows the inferior fit to data if $\eta=1.33 \mathrm{~Pa}$ s is assumed, constant with $\phi$.

At $2.25 \mathrm{MHz}$ the data for $c(\phi)$ are shown in Figure 8 . The solid curve shows the fit to the data allowing $\eta$ to vary according to Equation (24) with $K_{3}=5.2$, giving $\eta_{0}=1.0 \pm 0.1 \mathrm{~Pa}$ s. The broken curve fits Equation (7) to the data assuming a $\phi$-independent $\eta=1.33 \mathrm{~Pa}$ s. Again the fit is much improved by the procedure of allowing $\eta$ to vary with $\phi$.

\section{Shear rheology}

We have shown, above, the validity of Equation (22) for $\alpha$ at low volume fractions $(\phi<0.03)$, and also that of Equation (7) for $c$ at high volume fractions if the base fluid viscosity is assumed to vary with $\phi$ according to well-founded expectations of the effect of particle concentration on the bulk fluid rheology. In this section we use measurements of $\alpha$ and $c$ to obtain the shear viscosity, and elasticity, of fluids surrounding the ballotini.

Newtonian base fluids. Using as-received, unsieved, ballotini, measurements were made of $\alpha$ at $2.25 \mathrm{MHz}$ over the range $0<\phi<0.03$, using PPG 2025 as the base fluid, and obtaining $\eta$ using Equation (22). Similar measurements and analyses were made for sieved and unsieved ballotini surrounded by glycerol. Table 2 shows the data, $\eta_{\alpha}$ obtained from $\alpha$, and $\eta$ as measured using a Haake rheometer. The average discrepancy between $\eta_{x}$ and $\eta$ is about $10 \%$; this is within expectation allowing for possible sources of uncertainty.

Non-Newtonian base fluids. The technique described above for the Newtonian base fluids was applied to ballotini supported by the non-Newtonian base fluids. These were a water-based clay gel made from Bentopharm, and the oil-based clay gel made from Carbogel. Figure 9 compares $\eta_{\alpha}$ with a high shear rate viscosity $\eta_{\infty}$. This

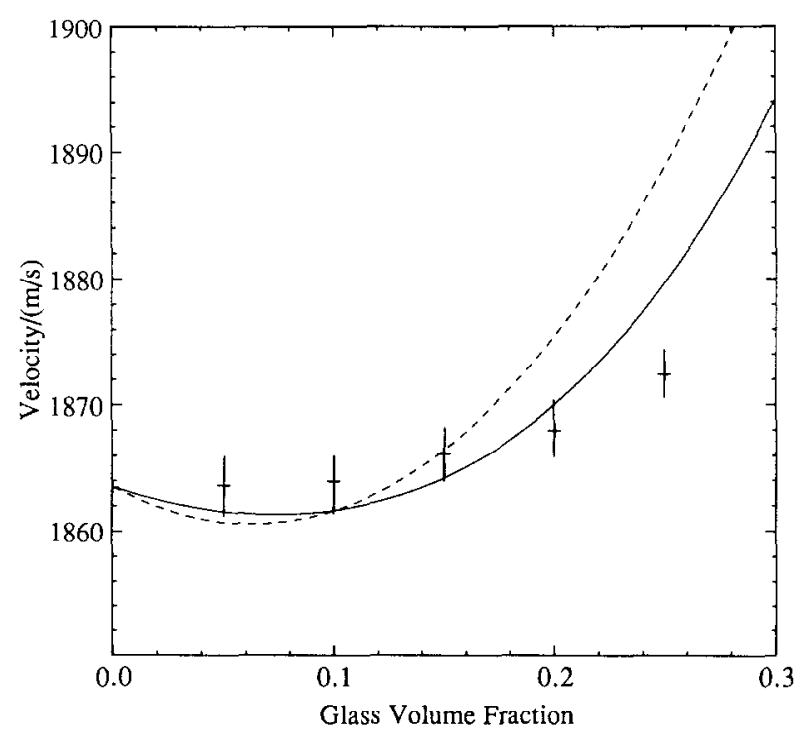

Figure 8 Velocity versus ballotini volume fraction for $a_{0}=15.8 \mu \mathrm{m}$ ballotini in glycerol at $20^{\circ} \mathrm{C}$ and $2.25 \mathrm{MHz}$ 
Table 2 Comparison of ultrasonic and rheological base fluid viscosities

\begin{tabular}{|lllllr|}
\hline Base fluid & $a_{0}(\mu \mathrm{m})$ & $\sigma$ & $(\alpha / \phi)\left(\mathrm{m}^{-1}\right)$ & $\eta_{\alpha}(\mathrm{mPas})$ & $\eta(\mathrm{mPas})$ \\
\hline PPG2025 $\left(20^{\circ} \mathrm{C}\right)$ & 31.5 & 0.40 & $1220 \pm 25$ & $360 \pm 25$ & $415 \pm 10$ \\
PPG2025 $\left(20^{\circ} \mathrm{C}\right)$ & 30.5 & 0.35 & $1220 \pm 25$ & $450 \pm 25$ & $415 \pm 10$ \\
glycerol $\left(22^{\circ} \mathrm{C}\right)$ & 20.5 & 0.21 & $1510 \pm 70$ & $1230 \pm 130$ & $1210 \pm 10$ \\
glycerol $\left(22^{\circ} \mathrm{C}\right)$ & 31.5 & 0.40 & $875 \pm 80$ & $1200 \pm 200$ & $1210 \pm 10$ \\
glycerol $\left(22^{\circ} \mathrm{C}\right)$ & 30.5 & 0.35 & $875 \pm 80$ & $1300 \pm 200$ & $1210 \pm 10$ \\
\hline
\end{tabular}

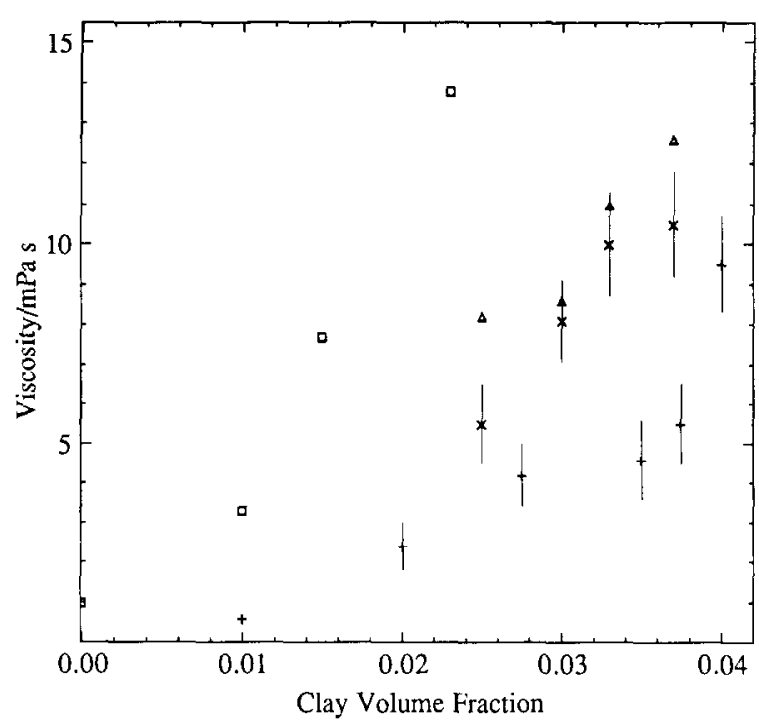

Figure 9 Viscosity versus clay volume fraction. Diagonal crosses; $\eta_{\alpha}$ for Carbogel. Upright crosses; $\eta_{\alpha}$ for Bentopharm. Triangles; $\eta_{\infty}$ for Carbogel. Squares: $\eta_{\infty}$ for Bentopharm

latter quantity was obtained by measuring the shear stress $\tau$ as a function of the shear rate $\dot{\gamma}$ using a Carrimed rheometer. The $\tau(\dot{\gamma})$ data were then fitted to the Casson relation

$\tau^{1 / 2}=\tau_{0}^{1 / 2}+\eta_{\infty}^{1 / 2} \dot{\gamma}^{1 / 2}$

to obtain $\eta_{\infty} ; \tau_{0}$ is the yield stress. Although a fair agreement exists between $\eta_{\alpha}$ and $\eta_{\infty}$ for the oil-based Carbogel, $\eta_{\infty} / \eta_{\alpha} \sim 3$ for the water-based Bentopharm.

This discrepancy was further investigated by measuring $c$ for the two non-Newtonian suspensions, and applying the analysis described earlier, using Equation (24) with $K_{3}=5.2$ to account for particle concentration, to obtain a viscosity $\eta_{c}$. Figures 10 and $I I$ show the fit of data to theory, giving $\eta_{c}=188 \mathrm{mPa} \mathrm{s}$ for the Bentopharm and $\eta_{c}=125 \mathrm{mPa}$ s for the Carbogel, at clay volume fractions of 0.025 and 0.037 , respectively. At this clay volume fraction, $\eta_{\alpha}$ was approximately $4 \mathrm{mPa}$ and $10 \mathrm{mPa}$. The large discrepancy between $\eta_{\alpha}$ and $\eta_{c}$, for both non-Newtonian fluids, is resolved if these fluids are allowed some shear elasticity $G$. This quantity is usually associated with fluids which have a yield stress $\tau_{0}$. It represents the Hookean response to small stresses of the structure originating from weak attractive bonds between clay particles. It is this structure which is destroyed at shear stresses exceeding $\tau_{0}$. Ultrasonic stresses in our experiments were negligible compared with $\tau_{0}$.

Assuming this interpretation, the theory presented in the section on the viscoelastic base fluid shows that the skin depth $\delta$ has to be replaced by $\delta^{\prime}-\delta^{\prime \prime}$ in the equations for $c$, and by $\delta^{\prime}+\delta^{\prime \prime}$ in those for $\alpha$. Hence, if $\eta_{\alpha}$ and $\eta_{c}$ are obtained from experimental data by interpretation

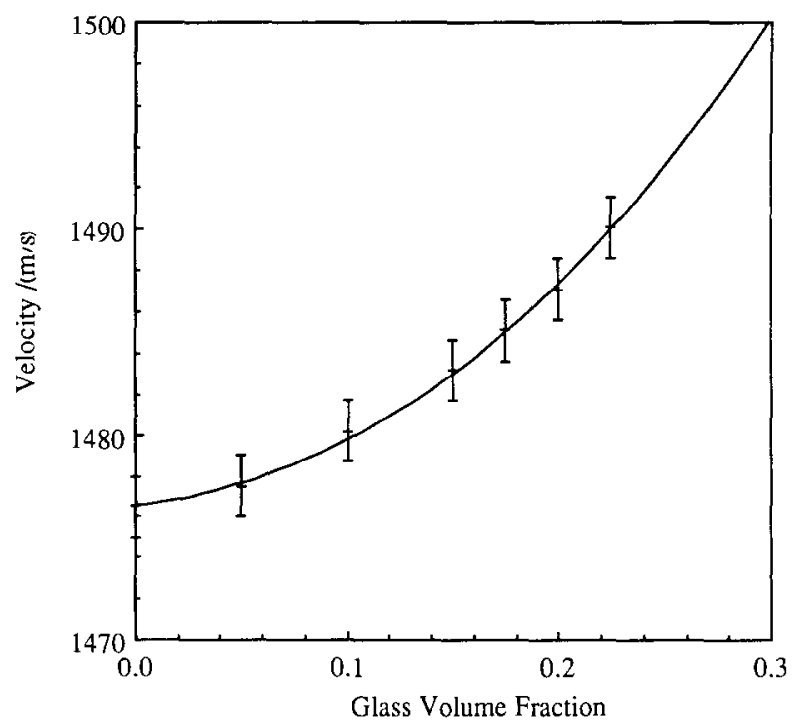

Figure 10 Velocity versus ballotini volume fraction for ballotini of $a_{0}=19.9 \mu \mathrm{m}$ in $2.5 \%$ by volume Bentopharm suspension at $22^{\circ} \mathrm{C}$ and $5 \mathrm{MHz}$. Markers show data; line shows theory

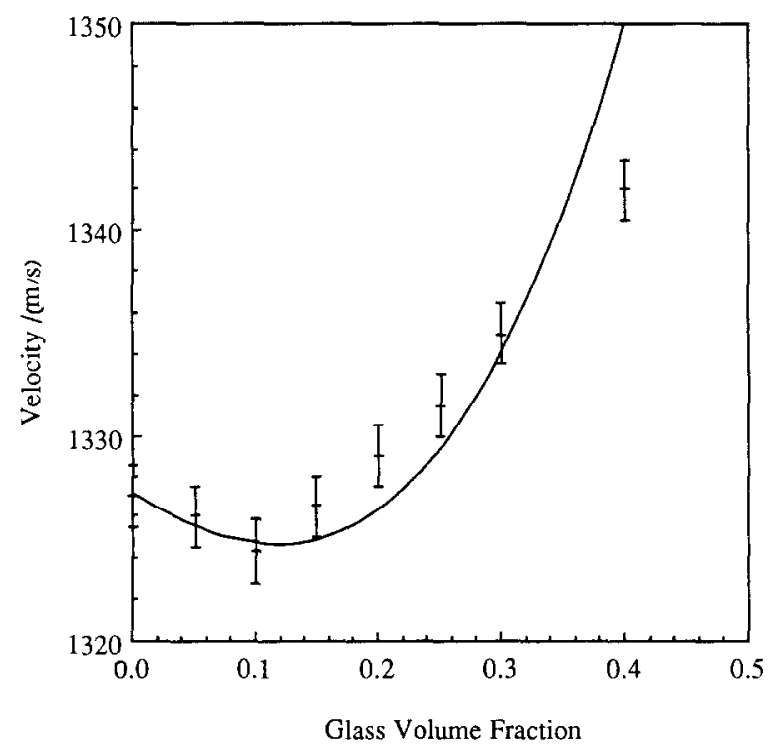

Figure 11 Velocity versus ballotini volume fraction for ballotini of $a_{0}=19.9 \mu \mathrm{m}$ in $3.7 \%$ by volume Carbogel suspension at $22^{\circ} \mathrm{C}$ and $5 \mathrm{MHz}$. Markers show data; line shows theory

through a purely viscous model, as done above, then

$\frac{\eta_{c}}{\eta_{\alpha}}=\left(\frac{\delta^{\prime}+\delta^{\prime \prime}}{\delta^{\prime}-\delta^{\prime \prime}}\right)^{2}=\frac{\left(1+Q^{2}\right)^{1 / 2}+Q}{\left(1+Q^{2}\right)^{1 / 2}-Q}$

A useful simplification of Equation (26) is that $\eta_{\mathrm{c}} / \eta_{\alpha}=$ $4 Q^{2}+2$ to within a $3 \%$ accuracy for $Q>1$. As $Q>0$ for a viscoelastic fluid then Equation (26) explains the experimentally-found result that $\eta_{c}>\eta_{a}$ for the Bentopharm and the Carbogel clay fluids. Using the previous results 
of 47 and 12.3 for $\eta_{c} / \eta_{\alpha}$ for these fluids then Equation (26) gives $Q=3.4$ and 1.6 for the Bentopharm and Carbogel fluids, respectively. If, pro tem, $\eta_{\infty}$, from Figure 9 is taken to approximate the fluid viscosity, an elasticity of $G=2 \mathrm{MPa}$ and $0.5 \mathrm{MPa}$ is obtainable for the Bentopharm and Carbogel fluids, respectively. These are not dissimilar to $G=18 \pm 5 \mathrm{MPa}$ found at $5 \mathrm{MHz}$ for a waterbase clay by a previous method ${ }^{5}$. The closer agreement shown in Figure 9 of $\eta_{\alpha}$ with $\eta_{\infty}$ for Carbogel, compared with the discrepancy between them for Bentopharm, may hence be related to the greater elasticity of the Bentopharm gel.

\section{Discussion}

For glass ballotini supported by Newtonian fluids, where the scattering is in the Rayleigh region, and where the viscous skin depth is small compared with the particle radius, our measured values of velocity and attenuation are in close agreement with the expressions for these quantities given by $\mathrm{Ament}^{8}$ and Urick ${ }^{6}$, respectively. For ballotini suspended in non-Newtonian fluids, the measured velocity and attenuation can be understood if allowance is made for the elasticity of the suspending fluids. It follows that care should be taken when using acoustic waves to investigate complex fluids where the continuous phase may be not purely viscous, e.g. by polymer gels in foods or by clay gels in drilling muds.

Recently, Derjaguin et al. ${ }^{15}$ have given experimental evidence that several molecular fluids possess an elasticity, typically in the $10^{4}-10^{5} \mathrm{~Pa}$ range. For our molecular fluids, e.g. glycerol, such elasticity would give $Q \sim 0.1$ at $1 \mathrm{MHz}$, and hence would be undetectable as a difference between $\eta_{\alpha}$ and $\eta_{c}$ in measurements where the fluid supports ballotini, and this is concordant with our results for these fluids. However, for water or similar lowviscosity fluids, $Q \sim 10$ would be expected, and differences between $\eta_{\alpha}$ and $\eta_{c}$ would be similar to that found by us for ballotini suspended in the viscoelastic clay fluids. Such experiments would form a test of the assertion of Derjaguin et al. $^{15}$

\section{Acknowledgement}

We should like to thank Dr J.V. Champion (Department of Physics, City of London Polytechnic) for his encouragement and support of this work.

\section{References}

1 McClements, D.J. Ultrasonic charactcrisation of cmulsions and suspensions Advances Colloid Interface Sci (1991) 37 33-72

2 Rahalkar, R.R., Gladwell, N., Javanaud, C. and Richmond, P. Ultrasonic behaviour of glass-filled polymer solutions $J$ Acoust Soc Am (1986) $8033-39$

3 Hayman, A.J. Ultrasonic properties of oilwell drilling muds IEEE 1989 Ultrasonic Symposium (1989) October 3-6, Montreal Canada $327-332$

4 Crowo, $\Lambda$. Ultrasound measurements on oil-based drilling mud Flow Meas Instrum (1990) 1 113-117

5 Champion, J.V., Langton, C.M., Meeten, G.H. and Sherman, N.E. Near-field ultrasonic measurement apparatus for fluids $\mathrm{Meas} \mathrm{Sci}$ Technol (1990) 1 786-792

6 Urick, R.I. The absorption of sound in suspensions of irregular particles $J$ Acoust SoC Am (1948) 20 283-289

7 Hay, A.E. and Mercer, D.G. A note on the viscous attenuation of sound in suspensions $J$ Acoust Soc Am (1989) 85 2215-2216

8 Ament, W.S. Sound propagation in gross mixtures $J$ Acoust Soc Am (1953) 25 638-641

9 McClements, D.J. and Povey, M.J.W. Ultrasonic velocity as a probe of emulsions and suspensions Advances Colloid Interface Sci (1987) 27 285-316

10 McClements, D.J. Comparison of multiple scattering theories with experimental measurements in emulsions J Acoust Soc Am (1992) $91849-853$

11 Heath, D. and Tadros, Th.F. Influence of $\mathrm{pH}$, electrolyte, and poly(vinyl alcohol) addition on the rheological characteristics of aqueous dispersions of sodium montmorillonite $J$ Colloid Interface Sci (1983) $93307-319$

12 Allegra, J.R. and Hawley, S.A. Attenuation of sound in suspensions and emulsions: theory and experiments $J$ Acoustical Soc Am(1972) 5 1545-1564

13 Batchelor, G.K. Transport processes of two-phase materials with random structure Ann Rev Fluid Mech (1974) $6227-255$

14 Van Der Werff, J.C. and De Kruif, C.G. Hard sphere colloidal dispersions: the scaling of rhcological properties with particle size volume fraction, and shear rate $J$ Rheology (1989) 33(3), 421-454

15 Derjaguin, B.V., Bazaron, U.B., Lamazhapova, Kh.D. and Tsidypov, B.D. Shear elasticity of low-viscosity liquids at low frequencies Phys Rev A (1990) 42 2255-2258 